\title{
CHARACTERISTICS OF MECHANICALLY FRACTIONATED AGGREGATES OF TWO CONTRASTING SOILS
}

\author{
Yulnafatmawita \\ J urusan Tanah F akultas Pertanian U niversitas Andalas Padang
}

\begin{abstract}
Tillage often decreases physical condition of agricultural land, especially aggregate degradation which causes land and environmental quality decreased. As aggregates disperse into single particles, chemical properties of the soil could change. The objective of this research was to study whether or not mechanical fractionation causes soil dispersion indicating by different chemical properties. Aggregates of two soils, Vertisol and Oxisol, were degraded by using puddler at 3 different energy rates $\left(40,60\right.$, and $150 \mathrm{~J} \mathrm{~kg}^{-1}$ soil minute $\left.{ }^{-1}\right)$ and then were separated into 3 different sizes $(2000-20,20-2,<2 \mathrm{um})$. Therefore, each soil sample would have 15 soil separates at different energy and aggregate size. The result showed that aggregate fractionation especially the fraction size, in general, affected EC, ESP, and CEC but not $\mathrm{pH}$ of both soils. The pattern of EC and CEC values seemed to be equal, the highest values were found at the smallest aggregate size $(<2 \mathrm{um})$. The CEC values of Oxisols did not affected by fractionation, while CEC values of Vertisols increased by decreasing aggregate size, and decreased by increasing energy applied. This indicated that Vertisol is easier to disperse than Oxisol.
\end{abstract}

Keywords: mechanical degradation, dispersion, bonding mechanism, bonding energy

\section{INTRODUCTION}

The dynamics of soil structural degradation due to energy input applied to land surfaces will be different among soils. It does not only depend on the the soil characteristics but also by the bond strength. Since the aggregates have different strength due to their bonding agents and mechanisms, the amount of soil broken or dispersed will be different among different soil types. Therefore, introducing the same amount of energy input to different soils should result in different degrees of degradation or breakdown.

The physical fractionation of soil aggregates may assist in investigations to understand how different size fraction of soil can have different chemical characteristics. As soil particles develop into aggregates in a hierarchical manner, fractionation should produce smaller aggregates that are natural components of the larger ones. For example as an impact of intensive cultivation, the large aggregates will be destroyed and broken into smaller aggregates. If the process persists for a long time, it is not impossible that the aggregates are dispersed into single particles, as the aggregates are arranged from single particles.

The first process of aggregation is flocculation of single clay particles which creates domain. Then, the domain will interact to other domains or bigger size particles with a help of binding agent to form compound soil structure as explained by Dexter (1988) through an arrangement presented in Figure 1. Therefore, if the soil aggregates are dispersed into single particles, the characteristics will be different from the aggregated particles. This is due to the fact that the surface area of the single particles will have free surfaces, while the aggregated ones have been associated with other cations or bonding agents. As a consequence, the ability of the single particles should be higher than those of aggregated ones to bind cations. Therefore, this research is aimed to study whether or not mechanical fractionation causes soil dispersion indicating by different chemical properties. 


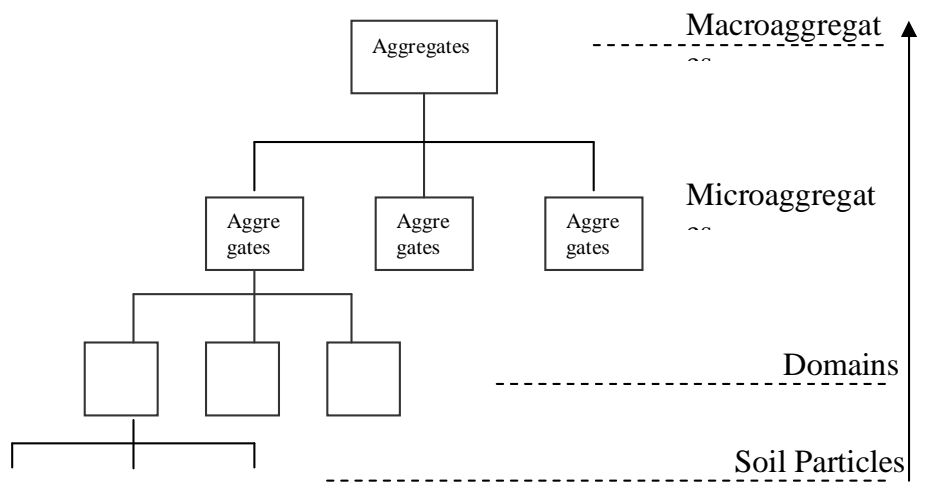

Figure 1. Hierarchical arrangement of soil aggregates (after Dexter, 1988)

The first process of aggregation is flocculation of single clay particles which creates domain. Then, the domain will interact to other domains or bigger size particles with a help of binding agent to form compound soil structure as explained by Dexter (1988) through an arrangement presented in Figure 1. Therefore, if the soil aggregates are dispersed into single particles, the characteristics will be different from the aggregated particles. This is due to thefact that the surface area of the single particles will have free surfaces, while the aggregated ones have been associated with other cations or bonding agents. As a consequence, the ability of the single particles should be higher than those of aggregated ones to bind cations. Therefore, this research is aimed to study whether or not mechanical fractionation causes soil dispersion indicating by different chemical properties.

\section{METHODOLOGY}

Two (2) soil types, Vertosol and Ferrosol (=Vertisol and Oxisol based on USDA Classification) (Isbel, 2002) were used in this laboratory study. The soils were sampled from 0-10 $\mathrm{cm}$ depth of different sites (Lawes Gatton and O'Reilly's Lamington, Queensland, Aust.) with different land use (annual cultivated and permanent pasture), respectively. Both soils have different dominant clay mineralogy, smectite and kaolinite, besides they have also different annual rainfall, 750 and $1900 \mathrm{~mm}$, respectively for
Soil samples were puddled (broken) by using puddler (Figure 2) at different energy levels (Fig. 3) and sizes into 15 different fractions (Fig. 4). Each soil fraction was analyzed for the $\mathrm{pH}$ (Hendershot, Lalande, and Duquette, 1993), EC (Janzen, 1993), CEC (Summer and Miller, 1994). ESP was calculated from the percentage of $\mathrm{Na}$ concentration to the CEC of the soils (Janzen, 1993), as follows:

$$
\mathrm{ESP}=\mathrm{Na}-\text { exch } * \text { 100/CEC) }
$$

Then, besides analyzing the fractionated and the bulk soils, the mean weighted value of fractionated soils was calculated, based on the soil fraction weight, as follows:

$$
\begin{aligned}
& \text { Weighted Mean }=\frac{\sum(\mathrm{X} * \mathrm{Wt})}{\sum \mathrm{Wt}} \\
& \mathrm{X}=\text { individual data } \\
& \mathrm{Wt}=\text { individual soil weight } \\
& \mathrm{n}=15 \\
& \sum_{1}=\text { Sum of the } 15 \text { fractions }
\end{aligned}
$$

The results were compared to the unfractionated bulk soils and a regression analysis was conducted to check how good the fractionation process was. The slope of the regression line should be close to 1 if the weighted average of the fractions is representative of the bulk soil, and no significant material loss occurred during fractionation.

For detail, characteristics of soils used are given in Table 1 . 
Vertisol and Oxisol (Stace et al.,1968).

Table 1. Characteristics of soils used in this experiment

\begin{tabular}{|c|c|c|c|c|c|c|c|c|c|c|}
\hline \multirow[t]{2}{*}{ No. } & \multirow[t]{2}{*}{ Code } & \multirow{2}{*}{$\begin{array}{l}\text { Great }^{1)} \\
\text { Soil } \\
\text { Group } \\
\end{array}$} & \multirow{2}{*}{$\begin{array}{l}\text { Austr. }{ }^{1)} \\
\text { Soil } \\
\text { Class }\end{array}$} & \multirow{2}{*}{$\begin{array}{l}\text { USDA: } \\
\text { Class }\end{array}$} & \multirow{2}{*}{$\begin{array}{l}\text { Clay }^{3)} \\
\text { Type } \\
\text { Dominant }\end{array}$} & \multirow{2}{*}{$\begin{array}{l}\mathrm{OC}^{4)} \\
\text { Conten } \\
\%\end{array}$} & \multirow{2}{*}{$\begin{array}{l}\text { Annual } \\
\text { Rainfal } \\
(\mathrm{mm})\end{array}$} & \multicolumn{3}{|c|}{ Texture $^{5)}(\%)$} \\
\hline & & & & & & & & sand & silt & clay \\
\hline 1 & $\mathrm{BE}$ & Black Earth & Vertosol & Vertiso & Smectite & 1.3 & $\pm 750^{3)}$ & 25 & 22 & 53 \\
\hline 2 & ORP & Krasnozem & Ferrosol & Oxisol & Kaolinite & 5.5 & $\pm 1900^{4)}$ & 9 & 21 & 70 \\
\hline & $\begin{array}{l}\text { 1) } \\
\text { 5) } Y \text { ( }\end{array}$ & & $\begin{array}{l}\text { Soil } \\
04)\end{array}$ & & & & & & & \\
\hline
\end{tabular}

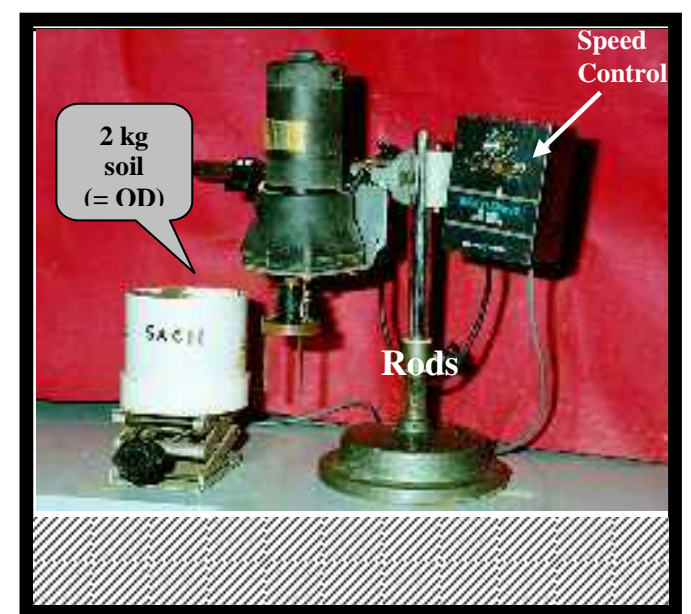

Figure 2. The puddling apparatus used to break soil aggregates in the laboratory at determined energy (Kirchhof and So, 1994)

\section{RESULTS AND DISCUSSIONS}

1. pH Values

In general, there was no effect of energy input rate and size of soil fractions on the $\mathrm{pH}$ values of both soils. Table 1 shows that the $\mathrm{pH}$ value of ORP was slightly lower than that of BE soil. ORP is a Ferrosol soil under a pasture land use in Lamington National Park, with $70 \%$ clay. It is developed from basic igneous rocks under high (750-2250 $\mathrm{mm}$ ) annual rainfall, therefore some of the basic cations was leached $(<50 \%$ base saturation) (Stace et al.,1968), and high $\left[\mathrm{H}^{+}\right]$results in low $\mathrm{pH}$ of this soil. As this soil is permanently pastured, high free $\mathrm{Fe}$ content, especially at $\mathrm{B} 2$ horizon with $>5 \%$ in fraction $<2$ $\mu \mathrm{m}$ (Isbell, 2002), combined with root

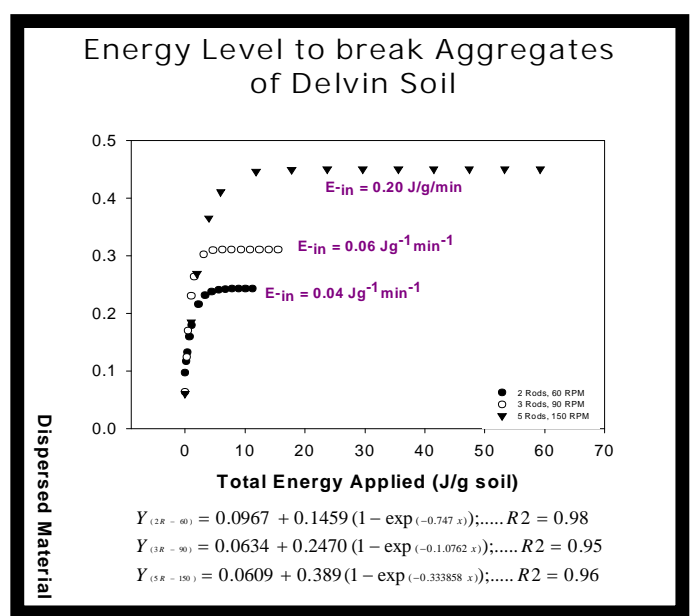

Figure 3. Energy level used to break soil aggregates

exudates from the grass, the soil has become slightly acidic than BE soil. Stace et al. (1968) stated that Oxisols may be mildly acid in the surface soil and may stay the same or decreases in the subsoil. Vertisol had $\mathrm{pH}$ values ranging from neutral to weakly basic. This agreed with the $\mathrm{pH}$ values of Vertisols which may be acid, neutral or alkaline reaction, but neutral and alkaline are more common (Clement et al., 1996).

Within each soil type, soil fractions did not show significant differences in $\mathrm{pH}$. The relationship between weighted mean of the fractions and the bulk soil showed a strong linear correlation with a slope 0.97 and the $\mathrm{R}=0.97$ (Figure 7). It means that puddling did not significantly affect the $\mathrm{pH}$ values of the bulk soil samples. 


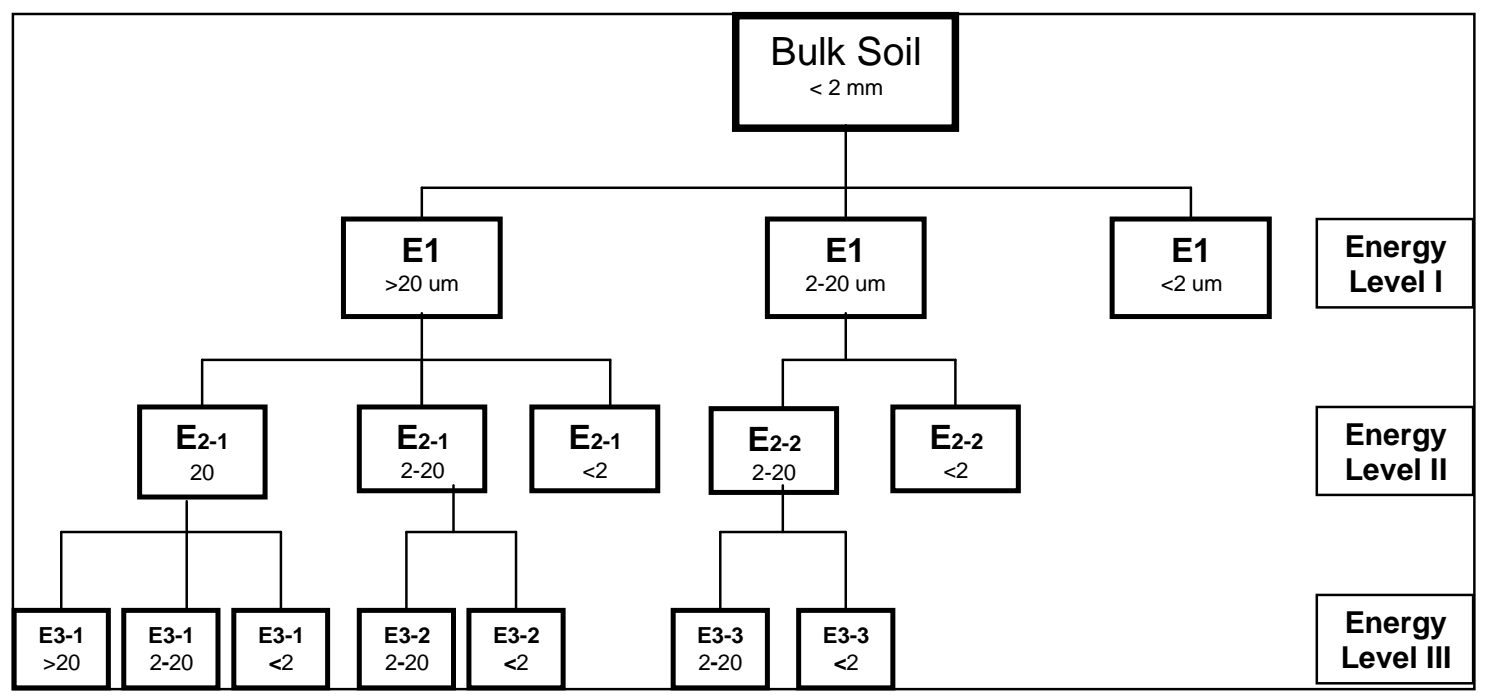

Figure 4. Fifteen (15) soil fractions resulted from fractionation process

\section{Electrical Conductivity (EC)}

Table 2 also presents the EC values of bulk and fractionated soil samples. The EC values of both soils shows the same pattern, significantly increased at the smallest soil fraction $(<2 \mathrm{um})$. The values tended to decrease by increasing energy input rate. It was believed that this was affected by two factors: the $1^{\text {st }}$ was due to the fractionation process which liberated the ions entrapped or associated with the mineral particles within the aggregates of the bulk soils. Especially, fraction $<2 \mu \mathrm{m}$ (= clay size) is assumed to collect all clay particles from the bulk soil, and therefore, to retain more cations than those of the larger fractions due to its much higher cation exchange capacity and specific surface area. The $2^{\text {nd }}$ might be due to an artifact during aggregate size separation, because the water soluble salt will be accumulated in the $<2 \mu \mathrm{m}$ fraction. When soil was suspended in water for the EC measurement, the deposited salts will be dissolved and remained in suspension causing high EC values.

Highest EC values of $<2 \mu \mathrm{m}$ fraction was clearly presented on Figure 5. For both BE and ORP soils, the EC values of the bulk soils were between the EC values of $<2$ and $>2 \mu \mathrm{m}$ fractions. There was no significant difference in the EC values between $>20$ and 2-20 $\mu \mathrm{m}$ fractions, but both were significantly $(\mathrm{P}<0.01)$ lower than the $<2 \mu \mathrm{m}$ fraction for BE soil. However, the EC value of the bulk soil was close to the values of fractions $>2 \mu \mathrm{m}$. This indicates that the EC values of fraction $>2 \mu \mathrm{m}$ were very much similar to the bulk soil while fraction $<2 \mu \mathrm{m}$ determined the weighted mean of the EC values. The highest EC values of $<2 \mu \mathrm{m}$ fraction resulted in poor correlation between weighted mean of the fractionated soils and the bulk soils (Figure 7).

\section{Cation Exchange Capacity (CEC)}

Table 3 presents the CEC values of the bulk and fractionated soils. CEC values of ORP either the bulk or the individual fraction was lower than $15 \mathrm{cmol} \mathrm{kg}^{-1}$, while BE bulk soil was higher than $15 \mathrm{cmol} \mathrm{kg}^{-1}$. Low CEC $(<15 \mathrm{c} \mathrm{mol} / \mathrm{kg})$ of ORP is associated with kaolinite (low surface area and low cation exchange capacity) (Filep, 1999) as the dominant clay mineral in the soil. The different size fraction did not cause different CEC values of ORP. This can be inferred that most of the fraction in each size was still aggregated.

$\mathrm{CEC}$ values of $\mathrm{BE}$ soil, on the other hand, ranged between $9-66 \mathrm{c} \mathrm{mol} \mathrm{kg}{ }^{-1}$, due to the dominant smectitic clay mineral, which has large surface area and CEC. Those values were significantly $(\mathrm{P}<0.01)$ 

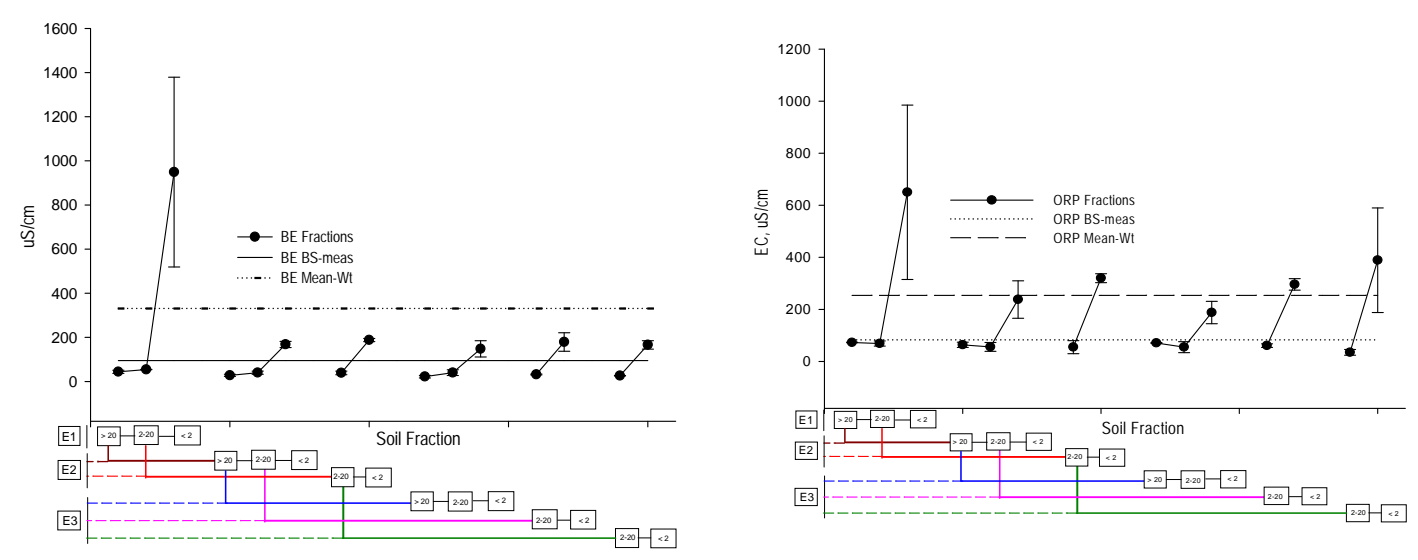

Figure 5. Electrical conductivity (EC) of fractionated BE and ORP soils ( $=$ SD with $n=2$ )

higher than the CEC values of the kaolinite soil group. CEC value of smectitic colloid ranges between 60-120 c mol kg-1 (Filep, 1999). Generally, CEC values of surface Vertisols were $37 \pm 8$ and Oxisols $5 \pm 3 \mathrm{c} \mathrm{mol} \mathrm{kg}^{-1}$ soil (Sposito,1989). The CEC values of the bulk soil samples in this project were consistent with the values reported.

Table 3. CEC ( $\mathrm{cmol} \mathrm{kg}^{-1}$ soil) values of fractionated soils

\begin{tabular}{|c|c|c|c|c|c|c|}
\hline \multicolumn{3}{|c|}{ Soil Fraction } & \multicolumn{2}{|c|}{ _CEC $\left(\mathrm{c} \mathrm{mol} \mathrm{kg}^{-1}\right)_{-}$} & \multicolumn{2}{|c|}{$\operatorname{ESP}(\%)$} \\
\hline Energy & $\begin{array}{c}\text { Sub- } \\
\text { Energy }\end{array}$ & $\begin{array}{l}\text { Size } \\
(\mu \mathrm{m})\end{array}$ & $\mathrm{BE}$ & ORP & $\mathrm{BE}$ & ORP \\
\hline \multirow[t]{3}{*}{ E1 } & 1 & $>20$ & 25.4 & 6.9 & 1.08 & 0.60 \\
\hline & & $2-20$ & 39.9 & 7.8 & 0.62 & 0.49 \\
\hline & & $<2$ & 65.9 & 9.4 & 5.72 & 3.23 \\
\hline \multirow[t]{5}{*}{ E-II } & 1 & $>20$ & 15.5 & 8.1 & 1.03 & 0.36 \\
\hline & & $2-20$ & 35.3 & 8.6 & 0.42 & 0.27 \\
\hline & & $<2$ & 63.7 & 9.9 & 2.28 & 6.01 \\
\hline & 2 & $2-20$ & 35.8 & 9.3 & 0.27 & 1.09 \\
\hline & & $<2$ & 63.5 & 8.6 & 1.35 & 1.63 \\
\hline \multirow[t]{7}{*}{ E-III } & 1 & $>20$ & 8.8 & 9.3 & 1.06 & 0.15 \\
\hline & & $2-20$ & 32.1 & 9.2 & 0.30 & 0.31 \\
\hline & & $<2$ & 63.0 & 9.7 & 1.68 & 2.47 \\
\hline & 2 & $2-20$ & 27.8 & 8.1 & 0.22 & 0.10 \\
\hline & & $<2$ & 62.5 & 9.1 & 1.28 & 0.57 \\
\hline & 3 & $2-20$ & 22.7 & 7.7 & 0.17 & 0.09 \\
\hline & & $<2$ & 61.5 & 8.8 & 0.97 & 0.78 \\
\hline \multicolumn{3}{|c|}{ Bulk Soil } & 28.3 & 8.7 & 1.42 & 1.85 \\
\hline \multicolumn{3}{|c|}{ Weighted Mean } & 34.4 & 8.8 & 1.12 & 1.35 \\
\hline
\end{tabular}


Within soil type, CEC values of both soils showed an opposite pattern, as presented in Figure 6 for the individual and the pooled CEC values of both soils. CEC values of $\mathrm{BE}$ soil fractions increased by decreasing fraction size, but there is no effect of fraction size on CEC values of ORP soil. High average CEC values (Table 4$)$ of the smallest $(<2$ um) size particle in BE soil could be an indicator of high clay particles instead of clay size aggregates in this fraction. In other words, most of the aggregates were dispersed into clay particles of BE soil (Vertisol) after applying energy input up to $150 \mathrm{~J} \mathrm{~kg}^{-1}$ soil. Since it is dominated by smectite (montmorillonite), being swelled and shrinked by water content, the soil is very susceptible to degradation as water is introduced. Therefore, it will have problem with cultivation.

It is assumed that ORP was still mostly aggregated at all levels, since the CEC values were not significantly different among the three size fractions at all energy levels applied. This could be due to high bond strength of the aggregates due to $\mathrm{OM}$ and $\mathrm{Fe}$ association (Krull and Skjemstad, 2003). As reported by Yulnafatmawita (2004) that the ORP (Oxisol) had high OC content (5.6\%) since it is permanently pastured ( \pm 100 years) and the soil originally has high $\mathrm{Fe}$ content which is classified into Ferrosol or Oxisol (Isbel, 2002; Stace et al, 1968). Additionally, the percentage of fraction < 2 um was still lower than the percentage of pure clay and the percentage of fraction $>20 \mu \mathrm{m}$ was still higher than the pure sand in the bulk soil (Yulnafatmawita, 2004). On the other hand, most of BE soil aggregates were broken into smaller ones and dispersed into single particles. It was identified from the percentage of fraction $>20 \mu \mathrm{m}$ was about the percentage of pure sand after the third energy rate applied. The percentage of pure sand increased as energy rate increased (Yulnafatmawita, 2004). Therefore, CEC values increase with decreasing size particles. This implies that the smaller the fraction size, the wider the surface area and the possibility to interact with $\mathrm{OM}$, therefore, the higher the chance of SOM to accumulate and be protected in that soil. However, since the characteristics of the smectitic mineral dominated this soil, the aggregates are easily to degrade while being wet.

In the $>20 \mu \mathrm{m}$ fraction of BE soil, there was a tendency of decreasing CEC values from 25.4 to 15.5 and to $8.8 \mathrm{c} \mathrm{mol} / \mathrm{kg}$ as energy input increased from 40 to 60 and to $150 \mathrm{~J} \mathrm{~kg}^{-1}$ soil $\mathrm{min}^{-1}$, respectively. This decrease correlated to the increase of the pure sand $(49,62,79 \%$ ), meaning less aggregated fractions, in this fraction size. As soil aggregates were not strongly bound due to the nature of the clay mineral dominant, smectite, which is affected by water content, the $\mathrm{BE}$ aggregates were intensively degraded as energy applied increased. The possibility of the BE soil aggregates to be dispersed into single particles is higher than the ORP soil.

Even though CEC values of fractionated soils showed different trends for different soil types, there was a good correlation between the weighted mean of the aggregate

Tabel 4. Pooled CEC data of BE and ORP soils

\begin{tabular}{lll}
\hline Fraction Size & \multicolumn{2}{c}{ CEC $(\mathrm{cmol} \mathrm{kg}-1)$} \\
\cline { 2 - 3 }$(\mathrm{m})$ & $\mathrm{BE}$ & ORP \\
\hline $2000-20$ & $12( \pm 3.3) *$ & $11( \pm 0,4)$ \\
$20-2$ & $30( \pm 4,3) * *$ & $10( \pm 0,3)$ \\
$<2$ & $66( \pm 2,0) * *$ & $10( \pm 0,8)$ \\
\hline
\end{tabular}

Note: Values in brackets are SD with $n=3(*) ; n=6(* *)$ 

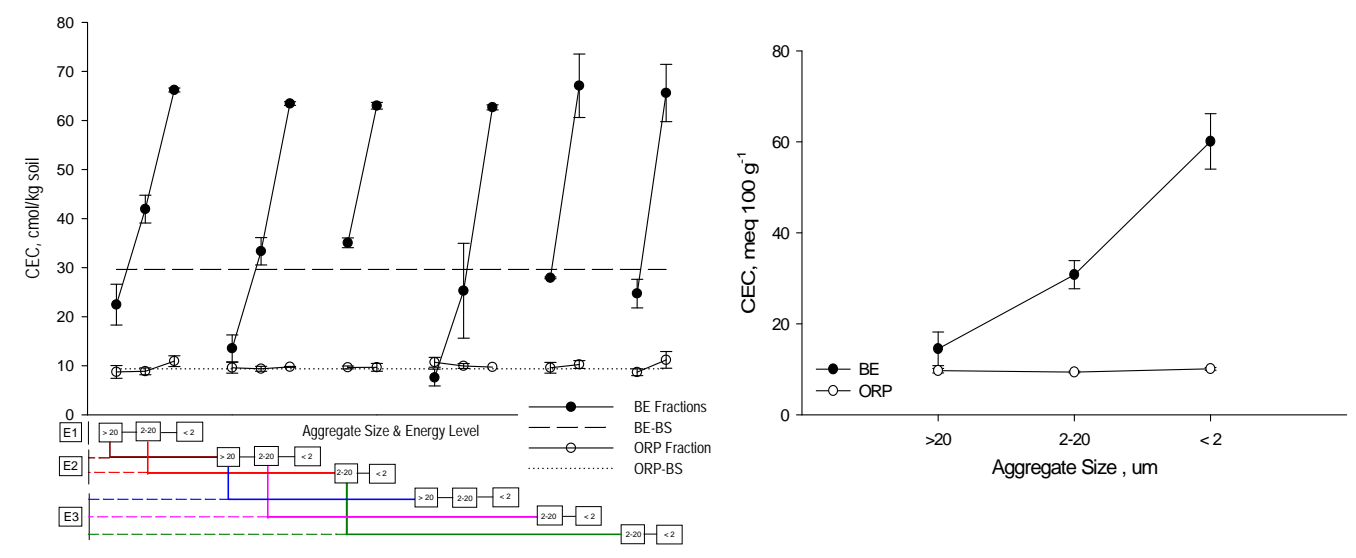

Figure 6. Cation exchange capacity values ( $\mathrm{c} \mathrm{mol} \mathrm{kg}{ }^{-1}$ soil) of fractionated-BE and -ORP soils for the each fraction and the pooled data $(=\mathrm{SD}$ with $\mathrm{n}=2)$
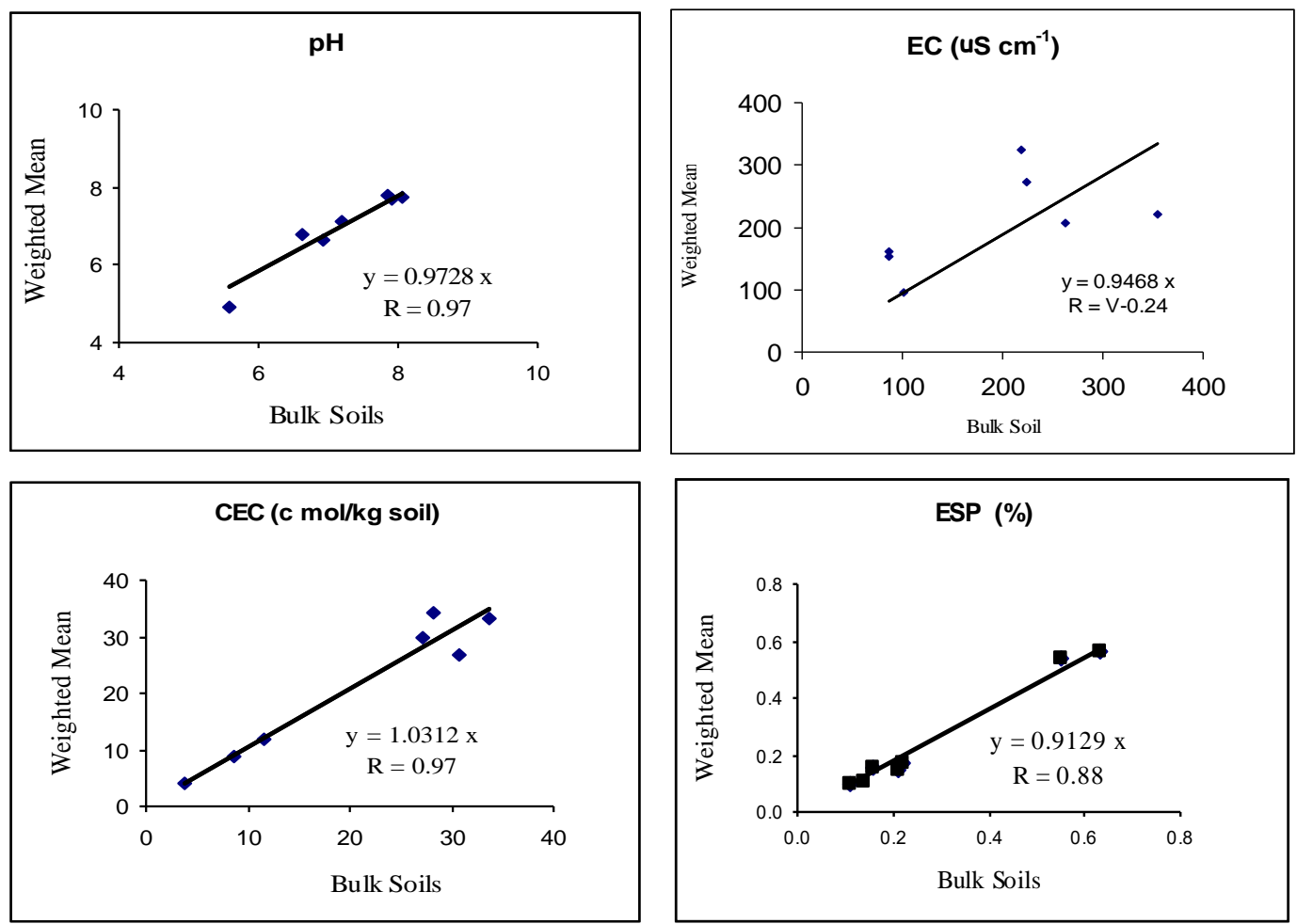

Figure 7. Correlation between the weighted mean and the bulk soils for (a) pH, (b) EC, (c), CEC, and (d) ESP through the origin

fractions and the bulk soils with an $\mathrm{R}=0.97$ and slope 1.03 (Figure 7). This indicates that the fractionation procedure did not cause significant material to be lost.

\section{Exchangeable Sodium Percentage (ESP)}

Table 3 also presents ESP values of bulk and fractionated soils as well as the weighted mean. The ESP values of the bulk soils were slightly higher than the weighted mean values for both soils, and the coefficient correlatiwas $\mathrm{R}=0.88$ and slope 0.91 (Figure 7). It means that fractionation did not caused sodium lost, even though the percentage among the size fractions showed a big difference. There was a tendency of high ESP pesentage at the smallest $(<2$ um) soil fraction for both soils and lowest at the largest (>20 um) fraction size. 


\section{CONCLUSIONS}

It can be concluded that:

2. In general, except EC, the values of soil characteristics showed a good correlation between the weighted mean and the bulk soils of aggregate fractions, this confirms that the fractionation method did not result in significant material losses.

3. Other than $\mathrm{pH}$ values which did not show a specific pattern for both soils, in general, fraction size tends to affect soil characteristics, but not energy input except for CEC values of Vertisol.

a. CEC Vertisol increased from $12( \pm 3.3)$ to $30( \pm 4.3)$ and to $66( \pm 2,0)$ by decreasing fraction size from $>20$ to $20-2$, and $<2$ um, and decreased from 25.4 to 15.5 and to $8.8 \mathrm{cmol} \mathrm{kg}^{-1}$ as energy input applied increased from 40 to 60 and $150 \mathrm{~J} \mathrm{~kg}^{-1}$ soil, respectively. CEC Oxisol, on the other hand, tended to be similar for all energy level applied and fraction

b. EC and ESP values showed the same pattern for both soils, highest in smallest fraction $(<2 \mathrm{um})$ at all energy level.

4. Soil chemical characteristics (especially CEC values) indicated that Vertisol was easier to degrade than Oxisol under the same energy input applied. However, it still needs more works to prove it.

\section{REFERENCES}

Clement, E.C., Dixon, J.B., and Wilding, L.P. (1996). Mineralogy and chemistry of Vertisols. In "Vertisols and technologies for their management", edited by N.Ahmad and A. Mermut. Development in Soil Sci. 24. Elsevier, Amsterdam, 549.

Dalal, R. C. and Mayer, R. J. (1986). Longterm trends in fertility of soils under continuous cultivation and cereal cropping in Southern Queensland (Australia): I. Overall changes in soil properties and trends in winter cereal yields. Aust. J. Soil Res., 24, 265-279.

Dexter, A. R. (1988). Advances in Characterization of Soil Structure. Soil Till. Res., 11, 199- 238.

Filep, G. (1999). Soil chemistry, processes and constituents. Akademiai Kiado, Budapest, 330.

Isbell, R.F. (2002). The Australian soil classification. Rev. ed., CSIRO Publishing, Collingwood, Austr, 144.

Janzen, H.H. (1993). Soluble salts. Chapter 18 in "Soil Sampling and Methods of Analysis" edited by M.R.Carter, Can.Soc. Soil Sci., Lewis Publisher, Boca Raton, 161-166.

Kirchhof, G. and So, H.B. (1994). Soil Puddling for rice production and its effect on soil structure and water percolation. In "Proceeding of the Second International Symposium on held on 7-11 February, Brisbane, Australia, 413-419.

Krull, E.S. and Skjemstad, J.O (2003) $\delta^{13} \mathrm{C}$ and $\delta^{15} \mathrm{~N}$ profiles in ${ }^{14} \mathrm{C}$-dated Oxisol and Vertisols as a function of soil chemistry and mineralogy. Geoderma, 112, 1-29.

Soil Survey Staff. (1998). Keys to soil taxonomy. $8^{\text {th }}$ Edition, USDA Nat. Res. Conserv. Service Publisher, Washington, D.C., USA, 326.

Sealing, Crusting and Hardsetting Soils: Productivity and Conservation",

Sposito, G. (1989). The chemistry of soils. Oxford Univ. Press, New York, 277.

Stace, H.C.T., Hubble, G.D., Brewer, R., Northcote, K.H. (1968). A handbook of Australian soils. Rellim Techn. Publication, Glenside, SA, 435.

Yulnafatmawita. 2004. Fractionation of soils based on bonding energy and aggregate size: A method for studying the effect of structural hierarchy on degradation process. PhD Thesis (being revised) Univ. of Queensland Brisbane, Australia, 199 pages. 